\title{
ANALISA TINGKAT PELAYANAN DAN KEBUTUHAN INFRASTRUKTUR PEDESTRIAN YANG MELINTASI JALAN T.P. RUSTAM EFFENDI PALEMBANG
}

\author{
Yules Pramona Z ${ }^{1)}$, Hariman Al faritzie ${ }^{2)}$, Gabriela Isnaini Putri ${ }^{3)}$ \\ Jurusan Teknik Sipil, Fakultas Teknik, Universitas Tridinanti Palembang \\ Jl. Kapten Marzuki No. 2446 Kamboja, Palembang 30129
}

\begin{abstract}
ABSTRAKSI
Jalan T.P. Rustam Effendi terletak di kecamatan Ilir Timur I Kota Palembang yang memiliki panjang 169,8 meter merupakan tujuan perjalanan karena mempuyai daya tarik sebagai pusat pertokoan dan perdagangan. Ramainya aktivitas perdagangan pada jam 8 pagi sampai dengan jam 5 sore di jalan T.P. Rustam Effendi ini ditambah lagi dengan pedagang kaki lima yang berjualan di area jalur pejalan kaki membuat kawasan ini selalu terjadi kemacetan. Karena permasalahan itulah maka dilakukan penelitian mengenai karakteristik pejalan kaki di kawasan tersebut, kapasitas dan tingkat pelayanannya (Level Of Services) apakah masih bisa menampung jumlah pejalan kaki yang ada di kawasan Jalan T.P. Rustam Effendi serta mengetahui tingkat kebutuhan masyarakat terhadap infrastrukur pejalan kaki (trotoar) di kawasan ini.

Variabel-variabel yang digunakan untuk mengetahui karakteristik pergerakan pejalan kaki adalah arus (flow), kecepatan (speed), kepadatan (density), dan ruang (space) untuk para pejalan kaki. Dari hasil survey didapatkan arus pejalan kaki tertinggi yaitu sebesar $17,433 \mathrm{ped} / \mathrm{m} / \mathrm{mnt}$, kecepatan tertinggi yaitu sebesar $53,575 \mathrm{~m} / \mathrm{mnt}$, kepadatan tertinggi yaitu sebesar $0,385 \mathrm{ped} / \mathrm{m} 2$ dan ruang terlebar yaitu 7,673 $\mathrm{m} 2 /$ ped.

Untuk menentukan Level of Service (LOS) trotoar terhadap karakteristik pejalan kaki digunakan dengan metode Highway Capacity Manual dan didapatkan LOS pada titik pengamatan 1 dan 2 termasuk tingkat pelayanan LOS C dan untuk titik pengamatan 3 dan 4 termasuk tingkat pelayanan LOS E. Sedangkan untuk menentukan Level of Services trotoar terhadap infrastruktrur digunakan metode Direktorat Jenderal Bina Marga dan didapatkan tingkat pelayanan pada titik pengamatan 1, 2, dan 4 termasuk tingkat pelayanan LOS A dan untuk titik pengamatan 3 termasuk tingkat pelayanan LOS B.

Untuk mengetahui tingkat kebutuhan masyarakat terhadap infrastruktur pejalan kaki (trotoar) ini digunakan metode scoring dengan melakukan wawancara/ interview langsung terhadap responden dan dari hasil survey dapat disimpulkan bahwa pada titik pengamatan 1 dan 2 sebanyak $83 \%$ responden menyatakan perlu akan adanya jalur pedestrian dan pada titik pengamatan 3 dan 4 sebanyak $65 \%$ responden menyatakan sangat perlu akan adanya jalur pedestrian. Selain tingkat kebutuhan masyarakat terhadap trotoar, juga dilakukan survey secara wawancara/ interview langsung mengenai tingkat penilaian masyarakat terhadap kondisi dari jalur pedestrian ke dalam 5 kelompok penilaian yaitu responden merasa trotoar yang ada saat ini sangat baik, baik, cukup baik, tidak baik atau sangat tidak baik untuk melayani para pejalan kaki yang melintasi jalur pedesrian tersebut dengan tingkat keamanan, kenyamanan, kebersihan, ketertiban, kondisi geometrik, dan fasilitas pedestrian sebagai tolak ukurnya.
\end{abstract}

Kata kunci : Karakteristik pejalan kaki, level of services, trotoar, pejalan kaki, infrastruktur pejalan kaki, tingkat kebutuhan infrastruktur pejalan kaki. 


\section{PENDAhuluan}

Jalan T.P. Rustam Effendi yang terletak di kecamatan Ilir Timur I, merupakan pusat kegiatan perdagangan di Palembang dan menjadi sorotan pada penelitian ini. Seringnya terjadi kemacetan lalu lintas yang dikarenakan banyaknya pedagang kaki lima yang tidak hanya mengambil trotoar untuk tempat berdagang, bahkan tidak jarang pedagang kaki lima juga menggunakan badan jalan sebagai tempat untuk berdagang. Letaknya yang strategis di tengah kota dan beraneka ragam barang yang ditawarkan merupakan potensi yang diperhitungkan sebagai kawasan perdagangan.

Keragaman barang-barang yang ditawarkan seperti, sandang, pangan, peralatan elektronik dan lain-lainnya, menjadikan kawasan ini pusat perbelanjaan yang ramai. Ramainya pejalan kaki di tambah pedagang kaki lima yang berjualan di trotoar membuat pejalan kaki berjalan berhimpitan. Ramainya aktivitas perdagangan pada jam 8 pagi sampai dengan jam 5 sore di jalan T.P. Rustam Effendi ini dengan panjang jalan 169,8 meter dan lebar jalan 8 meter ditambah lagi dengan pedagang kaki lima yang berjualan di area jalur pejalan kaki membuat kawasan ini selalu terjadi kemacetan. Karena permasalahan itulah maka dilakukan penelitian mengenai karakteristik pejalan kaki di kawasan tersebut serta kapasitas dan tingkat pelayanannya apakah masih bisa menampung jumlah pejalan kaki yang ada di kawasan Jalan T.P. Rustam Effendi. Dengan menggunakan metode Highway Capacity Manual (HCM) 2000 dan juga metode Dirjen Bina Marga, Petunjuk Perencanaan Trotoar akan dianalisa tingkat pelayanan pejalan kaki pada kawasan ini.

\section{TINJAUAN PUSTAKA}

\subsection{Definisi Jalur Pejalan Kaki}

Jalur pejalan kaki (pedestrian line) menurut Peraturan Presiden No. 43 tahun 1993 tentang Prasarana Jalan Bag. VII pasal 39 adalah termasuk fasilitas pendukung yaitu fasilitas yang disediakan untuk mendukung kegiatan lalu lintas dan angkutan jalan baik yang berada di badan jalan maupun yang berada di luar badan jalan, dalam rangka keselamatan, keamanan, ketertiban dan kelancaran lalu lintas serta memberikan kemudahan bagi pemakai jalan.

\subsection{Karakteristik Pejalan Kaki}

Variabel-variabel yang digunakan untuk mengetahui karakteristik pergerakan pejalan kaki arus (flow), kecepatan (speed) dan kepadatan (density), dan ruang (space) untuk pejalan kaki.

a. Kecepatan Berjalan (Walking Speed)

Kecepatan berjalan ialah kecepatan pejalan kaki saat berjalan dalam keadaan normal. Kecepatan berjalan dapat dihitung dengan mengambil waktu rata-rata pejalan kaki saat melintas jalan atau waktu rata-rata pada jarak yang tertentu.

b. Arus Pejalan Kaki (Pedestrian Flow)

Arus yaitu Pejalan kaki yang melintasi suatu titik pada penggal jalan dengan interval waktu tertentu di ukur dengan satuan Pejalan kaki per meter per menit.

c. Kepadatan (Density)

Kepadatan merupakan jumlah pejalan kaki per satuan luas trotoar tertentu.

d. Ruang (Space) Pejalan Kaki

Ruang pejalan kaki merupakan luas area rata-rata yang tersedia untuk masing-masing pejalan kaki yang dirumuskan dalam satuan $\mathrm{m} 2$.

\subsection{Pengertian Trotoar}

Trotoar adalah jalur pejalan kaki yang terletak di daerah manfaat jalan, diberi lapisan permukaan, diberi elevasi lebih tinggi dari permukaan perkerasan jalan, dan pada umumnya sejajar dengan jalur lalu lintas kendaraan. Fungsi utama trotoar adalah untuk memberikan pelayanan kepada pejalan kaki sehingga dapat meningkatkan kelancaran, keamanan dan kenyamanan pejalan kaki tersebut.

Trotoar juga berfungsi memperlancar lalu lintas jalan raya karena tidak terganggu atau terpengaruh oleh lalu lintas pejalan kaki. Ruang dibawah trotoar dapat digunakan 
sebagai ruang untuk menempatkan utilitas dan pelengkap jalan lainnya.

\subsection{Tingkat pelayanan Pejalan Kaki ( LOS Scale ) \\ Tingkat Pelayanan adalah} penggolongan kualitas traffic pada macammacam fraksi kapasitas maksimum. Tingkat pelayanan ini menunjukkan faktor kenyamanan.

Menurut Dirjen Bina Marga, Petunjuk Perencanaan Trotoar No.007/T/BNKT/1999, lebar trotoar harus dapat melayani volume pejalan kaki yang ada. Trotoar yang sudah ada perlu ditinjau kapasitas (lebar), keadaan dan penggunaannya apabila terdapat pejalan kaki yang menggunakan jalur lalu lintas kendaraan. Trotoar disarankan untuk direncanakan dengan tingkat pelayanan serendah-rendahnya C. Pada keadaan tertentu yang tidak memungkinkan trotoar dapat direncanakan sampai dengan tingkat pelayanan $\mathrm{E}$.

Tabel 2.1 Tingkat Pelayanan Pejalan Kaki Menurut Dirjen Bina Marga

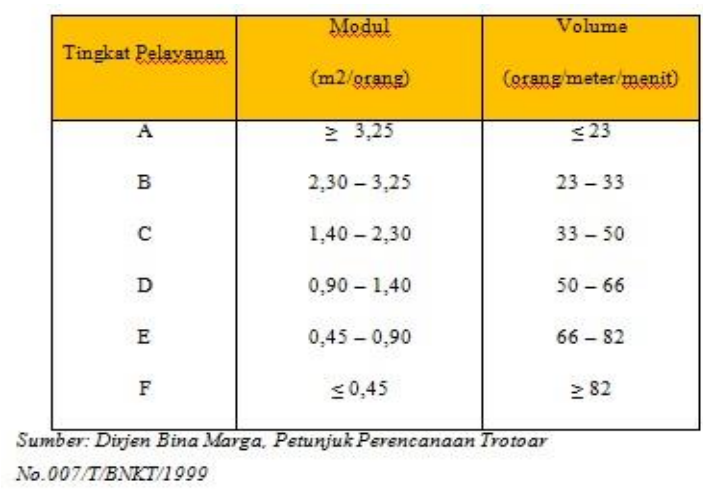

Syarat dalam menentukan tingkat pelayanan pada ruang pejalan kaki menurut Highway Capacity Manual, 2000 dalam hal ini digunakan beberapa cara sebagai berikut:

1. Menghitung nilai arus pejalan kaki pada interval 15 menit terbesar dari nilai arus pejalan kaki pada interval 15 menit lainnya.

$$
\mathrm{Q}_{15}=\frac{\mathrm{Nm}}{15 \mathrm{WE}}
$$

(Sumber : Highway Capacity Manual, 2000)

Dimana :

Q15 = Arus Pejalan kaki pada interval 15 menitan terbesar ( Org / m / mnt)

$\mathrm{Nm}=$ Jumlah Pejalan Kaki terbanyak pada interval 15 menitan, (Pejalan kaki) $\mathrm{WE}=$ lebar efektif ruang pejalan kaki.

2. Menghitung nilai ruang untuk pejalan kaki pada saat arus 15 menitan yang terbesar , digunakan rumus sebagai berikut :

$\mathrm{S}_{15}=\frac{1}{\mathrm{D}_{15}}$

(Sumber : Highway Capacity Manual, 2000)

Dimana :

S15 = Ruang Pejalan kaki pada saat arus 15 menitan yang terbesar $\left(\mathrm{m}^{2} /\right.$ Pejalan kaki)

D15 = Kepadatan pada saat arus 15 menitan yang terbesar (pejalan kaki $/ \mathrm{m}^{2}$ )

3. Membuat perbandingan antara volume berbanding kapasitas yang merupakan variabel penting dalam menentukan tingkat pelayanan.

\subsection{Tingkat Kebutuhan Infrastruktur Pejalan Kaki}

Dalam buku Khisty (2003), faktorfaktor yang harus dipertimbangkan dalam merancang fasilitas pejalan kaki sesuai dengan kebutuhan dari pejalan kaki, antara lain :

1. Faktor kenyamanan (Comfort) : seperti perlindungan dari cuaca, tempat berteduh, halte dan tempat lainnya.

2. Faktor kemudahan (Convenience) : jarak jalan, kelurusan berjalan, tangga untuk orang lanjut usia, kemiringan jalan, posisi tanda arah, peta petunjuk dan kemudahan-kemudahan lain yang membuat perjalanan dengan berjalan kaki menjadi mudah dan tidak rumit.

3. Faktor keselamatan (Safety) : pemisah antara lalu lintas kendaraan dengan pejalan kaki, jalur trotoar hanya digunakan untuk pejalan kaki. 
4. Faktor keamanan (Security) : seperti pencahayaan / penerangan, garis arah, bebas dari gangguan kejahatan.

5. Faktor ekonomi (Economy) : meminimalkan keterlambatan pejalan.

\subsection{Penentuan Perhitungan Sampel}

Sampel adalah sebagian dari populasi. Artinya tidak akan ada sampel jika tidak ada populasi. Populasi adalah keseluruhan elemen atau unsur yang akan kita teliti. Penelitian yang dilakukan atas seluruh elemen dinamakan sensus. Idealnya, agar hasil penelitiannya lebih bisa dipercaya, seorang peneliti harus melakukan sensus. Namun karena sesuatu hal peneliti bisa tidak meneliti keseluruhan elemen tadi, maka yang bisa dilakukannya adalah meneliti sebagian dari keseluruhan elemen atau unsur tadi.

Cara menentukan jumlah sampel penelitian menggunakan tabel ataupun rumus cukup bervariasi. Misalnya ada yang menggunakan rumus seperti rumus Slovin maupun tabel pengambilan sampel yang cukup populer yaitu Tabel Krejcie dan Morgan.

\section{METODOLOGI PENELITIAN 3.1. Umum}

$\mathrm{Bab}$ ini membahas tentang metodologi penelitian yang digunakan pada penelitian di Jalan T.P. Rustam Effendi berbasis Pedestrian dapat dilihat pada gambar 3.1 yang menjadi bagan alir penelitian.

\subsection{Identifikasi Masalah}

Dalam tahap ini penulis mempelajari tentang latar belakang analisa tingkat pelayanan jalur pejalan kaki di Jalan T.P. Rustam Effendi, juga bagaimana mengidentifikasi masalah yang timbul dan merumuskannya menjadi suatu tujuan yang harus diselesaikan untuk mengatasi permasalahan.

\subsection{Studi Literatur}

Tahap ini adalah tahap dimana dasardasar teori didapat dari berbagai sumber literatur seperti : referensi buku-buku acuan, peraturan-peraturan yang digunakan, perumusan yang digunakan, serta laporan penelitian atau studi terdahulu yang terkait dengan topik dipelajari untuk menunjang studi ini. Literatur yang menunjang adalah referensireferensi yang mengungkapkan teori-teori mengenai materi-materi yang dipakai pada tugas akhir ini. Teori-teori tersebut antara lain mengenai :

1. Gambaran umum Kota Palembang

2. Definisi jalur pejalan kaki

3. Karakteristik Pejalan Kaki

4. Definisi Trotoar

5. Tingkat pelayanan pejalan kaki (LOS Scale)

\subsection{Metode Pengumpulan Data \\ 3.4.1 Teknik Pengumpulan Data}

Dalam pengumpulan data untuk tugas akhir ini adalah : Teknik observasi langsung yakni teknik pengumpulan data dimana penyelidik mengadakan pengamatan secara langsung terhadap gejala-gejala subyek yang diselidiki baik pengamatan itu dilakukan dalam situasi sebenarnya maupun dalam situasi bantuan. Dalam penelitian ini akan menggunakan analisa data dan metode deskriptif kualitatif dan kuantitatif.

\subsubsection{Jenis Data dan Cara Perolehannya}

a. Data Primer

Dalam memperoleh data primer dilakukan dengan membuat suatu rencana survey, survey pendahuluan dan pelaksanaan survey. Survey dilapangan dilakukan pada saat jam-jam sibuk (peak hours) pagi, siang dan sore hari di sepanjang jalan T.P. Rustam Effendi.

b. Data Sekunder

Pengumpulan data sekunder, langkahlangkah yang dilakukan adalah dengan melakukan pengumpulan data yang sudah ada yang berhubungan dengan penelitian. 


\subsubsection{Pemilihan Lokasi dan Waktu Pengumpulan Data}

Lokasi yang dipilih untuk pengumpulan data tingkat pelayanan trotoar harus memenuhi kriteria :

1. Jalur khusus pejalan kaki yang melintasi kawasan jalan T.P. Rustam Effendi.

2. Terdapat fluktuasi arus pejalan kaki seperti arus puncak dan arus normal

3. Jalur pejalan kaki yang lurus dan tidak berbelok

4. Dapat dengan mudah melakukan pengamatan

5. Jalur yang sering dilewati pejalan kaki Pengambilan data dilakukan pada pada jam-jam sibuk yaitu pada pagi, siang dan sore hari tepatnya di akhir pekan pada tanggal awal bulan, mengingat trend berbelanja masyarakat yang meningkat di waktu-waktu tersebut.

\subsection{Pengolahan Data}

Pengolahan data primer yang didapat dari lapangan dengan menggunakan metode Highway Capacity Manual (HCM) 2000 yang dimasukkan ke dalam bahasa program microsoft excel.

a. Perhitungan Arus Pejalan Kaki

Arus pejalan kaki dihitung berdasarkan seluruh pejalan kaki yang melewati penggal jalan yang diamati. Pengamatan dengan interval waktu 15 menit.

\section{b. Perhitungan Kecepatan Berjalan (Walking Speed)}

Data yang digunakan dalam perhitungan kecepatan berjalan kaki adalah waktu tempuh pejalan kaki yang melewati penggal jalan pengamatan. Panjang penggal jalan pengamatan ditentukan sepanjang 15 meter, dengan waktu tempuh menggunakan satuan menit, sehingga satuan yang diperoleh dalam meter per menit.

c. Perhitungan Kepadatan (Density) Pejalan kaki

Kepadatan ( density ) diperoleh dari variabel-variabel yang telah dicari pada bagian sebelumnya yaitu Arus (flow) dan kecepatan (speed).

d. Perhitungan Ruang ( Space ) Pejalan kaki
Ruang yang tersedia untuk pejalan kaki diperoleh dari persamaan (2.8). sebagai contoh, pada hari minggu pukul 08.00 - 08.15 WIB diketahui besarnya kepadatan adalah 0,0033 pejalan kaki / $\mathrm{m} 2$, maka luasnya ruang yang tersedia untuk pejalan kaki adalah: (asumsi, hanya untuk contoh / ilustrasi)

$\mathrm{S}=1 / \mathrm{D}=1 / 0,0033=303,03 \mathrm{~m} 2 /$ pejalan

kaki.

e. Kebutuhan Infrastruktur Fasilitas Pejalan Kaki Melalui Metode Kuesioner

Data kebutuhan fasilitas pejalan kaki yang ada di lokasi Jalan T.P. Rustam Effendi didapatkan dari interview langsung, yaitu pertanyaanpertanyaan yang harus dijawab oleh responden (pejalan kaki) mengenai tingkat kebutuhan dan tingkat kenyamanan dari infrastruktur pejalan kaki (trotoar) yang ada saat ini pada kawasan wilayah penelitian.

\subsection{Analisa Data}

a. Analisa Data Kuantitatif

Analisa data kuantitif dapat diperoleh dari hasil pengolahan data primer pedestrian sehingga didapatkan nilai untuk kecepatan berjalan, volume pedestrian, serta ruang pedestrian. Hasil pengolahan data primer tersebut dibandingkan terhadap standar Highway Manual Capacity (HCM) dan juga terhadap standar Dirjen Bina Marga pada buku Petunjuk Perencanaan Trotoar No.007/T/BNKT/1999 sehingga dapat ditentukan tingkat pelayanan pejalan kaki pada kawasan yang ditinjau dan juga menentukan saran-saran sebagai solusi permasalahan yang ada agar tingkat kenyamanan pejalan kaki tetap terjaga dikemudian harinya.

b. Analisa Data Kualitatif

Analisa yang digunakan dalam menentukan tingkat kebutuhan infrastruktur dan penilaian terhadap kondisi trotoar adalah analisa data kualitatif dengan pembobotan (metode scoring) pada penyajian data kuisioner. Survey yang diterapkan yaitu interview langsung dengan pejalan kaki yang melintasi kawasan penelitian. Analisa kebutuhan infrastruktur pejalan kaki (trotoar) pada kawasan jalan T.P. Rustam Effendi yaitu: 1. Survey tingkat kebutuhan infrastruktur 2. Survey penilaian terhadap kondisi trotoar 


\section{ANALISA DAN PEMBAHASAN} 4.1 Hasil Penelitian

Jalan T.P. Rustam Effendi merupakan pusat kegiatan perdagangan di kota Palembang dan menjadi sorotan pada penelitian ini. Seringnya terjadi kemacetan lalu lintas yang dikarenakan banyaknya pedagang kaki lima yang tidak hanya mengambil trotoar untuk tempat berdagang, bahkan tidak jarang pedagang kaki lima juga menggunakan badan jalan sebagai tempat untuk berdagang. Letaknya yang strategis di tengah kota dan beraneka ragam barang yang ditawarkan merupakan potensi yang diperhitungkan sebagai kawasan perdagangan.

Penelitian ini dibagi menjadi empat titik pengamatan, dimana titik pengamatan 1 dan titik pengamatan 4 terletak di ruas kiri Jalan T.P. Rustam Effendi, sedangkan titik pengamatan 2 dan titik pengamatan 3 terletak di ruas kanan Jalan T.P. Rustam Effendi. Lokasi pembagian titik pengamatan dapat dilihat pada gambar 4.1 dibawah ini:

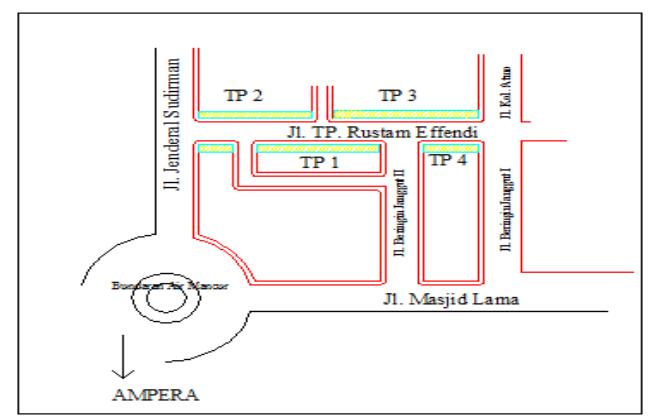

Sumber : Hasil Pengamatan

\subsubsection{Volume Pejalan Kaki}

Pengamatan volume pejalan kaki adalah pengamatan terhadap jumlah pejalan kaki yang masuk ke lokasi yang diamati, pengamatan jumlah pejalan kaki ini dilakukan dengan menghitung jumlah pejalan kaki yang masuk ke lokasi pengamatan yang dilakukan dalam interval 15 menit.

Setelah dilakukan pengamatan per titik dengan interval waktu per 15 menit, maka akan didapatkan rekapitulasi volume pejalan kaki yang telah dilakukan selama 10 jam dari pukul 07.00 - 17.00. Rekapitulasi volume pejalan kaki pada setiap titik di Jalan T.P. Rustam Effendi dapat dilihat pada tabel 4.1 dibawah ini :

Tabel 4.1 Rekapitulasi Volume Pejalan Kaki

\begin{tabular}{|c|c|c|c|c|}
\hline \multirow{2}{*}{ No } & \multirow{2}{*}{ Titik } & \multicolumn{3}{|c|}{ Jumlah Pejalan Kaki } \\
\cline { 3 - 5 } & Pengamatan & Pria & Wanita & Jumlah \\
\hline 1 & TP 1 & 2259 & 2388 & 4647 \\
\hline 2 & TP 2 & 1284 & 1242 & 2526 \\
\hline 3 & TP 3 & 2907 & 5868 & 8775 \\
\hline 4 & TP 4 & 1886 & 2069 & 3955 \\
\hline
\end{tabular}

Sumber : Pengolahan Data

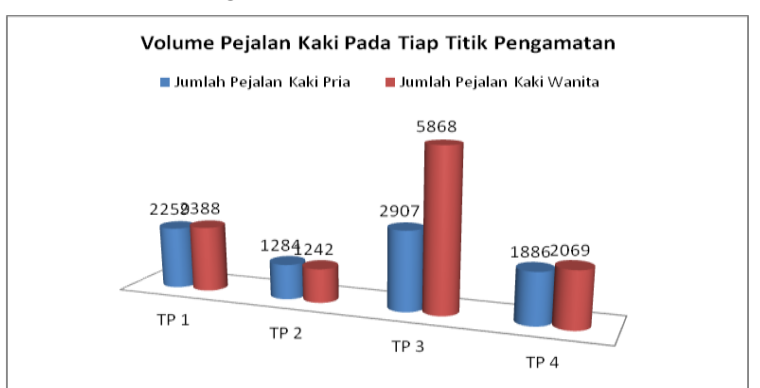

Gambar 4.2 Grafik Jumlah Volume Pejalan Kaki Pada Jalan T.P. Rustam Effendi

\subsubsection{Waktu Tempuh}

Pada penelitian ini alat yang digunakan adalah camcorder dan stopwatch, waktu tempuh pejalan kaki dicatat dengan menetapkan ruas pengamatan sepanjang kurang lebih 10 - 15 meter tergantung pada jarak pandang pada setiap titik pengamatan pada trotoar yang batasnya diberi tanda yang dapat dilihat dengan jelas oleh surveyor.

Untuk pendataan waktu tempuh pejalan kaki dibedakan pria dan wanita. Waktu tempuh dapat dilihat pada Tabel 4.2 sebagai berikut :

Tabel. 4.2 Waktu Tempuh Rata - rata

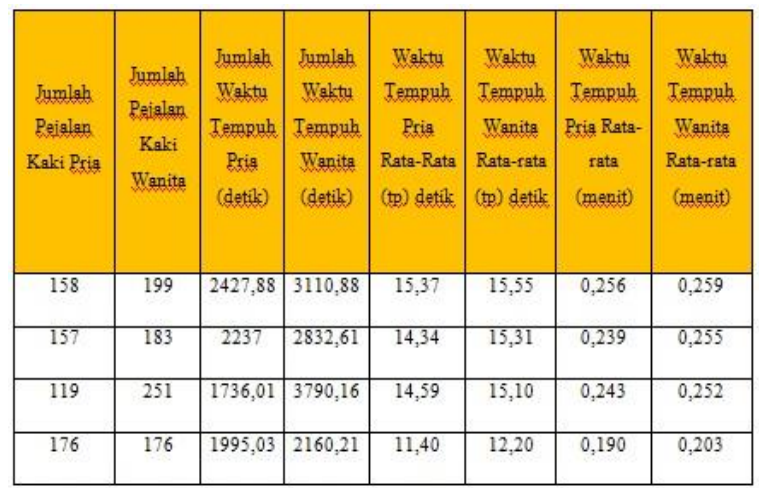

Sumber : Pengolahan Data 


\subsection{Karakteristik Pejalan Kaki}

Variabel-variabel yang digunakan untuk mengetahui karakteristik pergerakan pejalan kaki arus (flow), kecepatan (speed) dan kepadatan (density), dan ruang (space) untuk pejalan kaki.

\subsection{Tingkat Pelayanan Pejalan Kaki} Kondisi Eksisting tingkat pelayanan pejalan kaki Jalan T.P. Rustam Effendi menurut Highway Capacity Manual dapat dilihat pada Tabel 4.3 berikut:

Tabel. 4.3 Kondisi Eksisting Tingkat Pelayanan Pejalan Kaki Menurut Highway Capacity Manual

\begin{tabular}{|c|c|c|c|c|c|}
\hline $\begin{array}{c}\text { Titik } \\
\text { Pengamatan }\end{array}$ & $\begin{array}{c}\text { Ruang } \\
\text { (m2/ped) }\end{array}$ & $\begin{array}{c}\text { Arus } \\
\text { (ped/m/mnt) }\end{array}$ & $\begin{array}{c}\text { Kecepatan } \\
\text { (m/dtk) }\end{array}$ & V/C & $\begin{array}{c}\text { Los (Level of } \\
\text { Senices) High } \\
\text { Copocity Monua) }\end{array}$ \\
\hline TP1 & 6,882 & 7,101 & 0,81 & 0,42 & $\mathrm{C}$ \\
\hline TP 2 & 5,699 & 7,901 & 0,75 & 0,43 & $\mathrm{C}$ \\
\hline TP 3 & 2,597 & 17,433 & 0,75 & 0,96 & E \\
\hline TP 4 & 7,673 & 6,982 & 0,89 & 0,84 & E \\
\hline
\end{tabular}

Sumber : Pengolahan Data

\section{Kondisi Eksisting tingkat} pelayanan pejalan kaki Jalan T.P. Rustam Effendi menurut Direktorat Jendra Bina Marga dapat dilihat pada Tabel 4.4 dibawah ini:

Tabel. 4.4 Kondisi Eksisting Tingkat Pelayanan Pejalan Kaki Menurut Direktorat Jendral Bina Marga

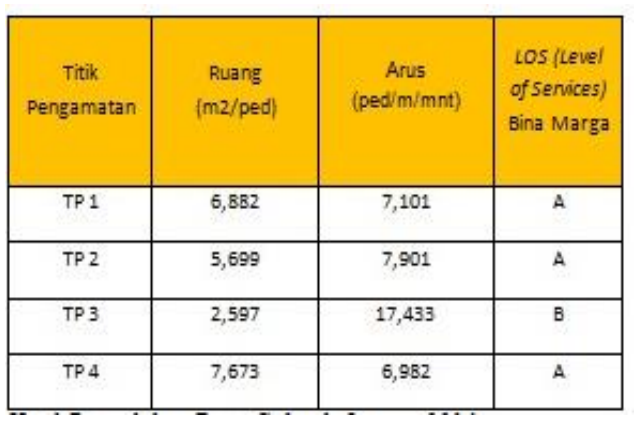

Sumber : Pengolahan Data

\subsection{Tingkat Kebutuhan dan Penilaian Masyarakat Terhadap Jalur Pedestrian Jalan T.P. Rustam Effendi}

Berdasarkan survey dengan metode kuesioner mengenai penilaian masyarakat terhadap jalur pejalan kaki dari segi keamanan, kenyamanan, kebersihan, ketertiban, kondisi geometrik dan fasilitas pedestrian maka di dapatkan hasil sebagai berikut :

Tabel 4.5 Rekapitulasi Kuisioner Tingkat Penilaian Masyarakat terhadap Jalur Pedestrian pada Titik Pengamatan 1

\begin{tabular}{|c|c|c|c|c|c|c|}
\multirow{2}{*}{ No Kriteria } & \multirow{2}{*}{} & \multicolumn{5}{|c|}{ Jumlah (\%) } \\
\cline { 3 - 7 } & & STB & TB & CB & B & SB \\
\hline 1 & Keamanan & 0 & 2 & 29 & 69 & 0 \\
\hline 2 & Kenyamanan & 0 & 23 & 57 & 20 & 0 \\
\hline 3 & Kebersihan & 5 & 55 & 34 & 6 & 0 \\
\hline 4 & Ketertiban & 4 & 31 & 58 & 7 & 0 \\
\hline 5 & Kondisi Geometrik & 0 & 6 & 35 & 59 & 0 \\
\hline 6 & Fasilitas Pedestrian & 10 & 72 & 17 & 1 & 0 \\
\hline
\end{tabular}

Sumber : Pengolahan Data

Keterangan :

STP = Sangat tidak perlu

SP = Sangat Perlu

$\mathrm{CP}=$ Cekup perlu

$\mathrm{P} \quad=$ Perlu

$\mathrm{SP} \quad=$ Sangat perlu

Tabel 4.6 Rekapitulasi Kuisioner Tingkat Penilaian Masyarakat terhadap Jalur Pedestrian pada Titik Pengamatan 2

\begin{tabular}{|c|l|c|c|c|c|c|}
\hline \multirow{2}{*}{ No Kriteria } & \multirow{5}{|c|}{ Jumlah (\%) } \\
\cline { 3 - 8 } & & STB & TB & CB & B & SB \\
\hline 1 & Keamanan & 0 & 9 & 42 & 49 & 0 \\
\hline 2 & Kenyamanan & 0 & 5 & 60 & 35 & 0 \\
\hline 3 & Kebersihan & 0 & 37 & 58 & 5 & 0 \\
\hline 4 & Ketertiban & 0 & 44 & 54 & 2 & 0 \\
\hline 5 & Kondisi Geometrik & 0 & 15 & 57 & 28 & 0 \\
\hline 6 & Fasilitas Pedestrian & 0 & 15 & 57 & 28 & 0 \\
\hline
\end{tabular}

Tabel 4.6 Rekapitulasi Kuisioner Tingkat Penilaian Masyarakat terhadap Jalur Pedestrian pada Titik Pengamatan 3

\begin{tabular}{|c|l|c|c|c|c|c|}
\hline \multirow{2}{*}{ No Kriteria } & \multicolumn{5}{c|}{ Jumlah (\%) } \\
\cline { 3 - 8 } & & STB & TB & CB & B & SB \\
\hline 1 & Keamanan & 0 & 5 & 63 & 32 & 0 \\
\hline 2 & Kenyamanan & 0 & 32 & 62 & 6 & 0 \\
\hline 3 & Kebersihan & 7 & 73 & 18 & 2 & 0 \\
\hline 4 & Ketertiban & 10 & 76 & 14 & 0 & 0 \\
\hline 5 & Kondisi Geometrik & 0 & 23 & 53 & 24 & 0 \\
\hline 6 & Fasilitas Pedestrian & 8 & 79 & 13 & 0 & 0 \\
\hline
\end{tabular}


Tabel 4.7 Rekapitulasi Kuisioner Tingkat Penilaian Masyarakat terhadap Jalur Pedestrian pada Titik Pengamatan 4

\begin{tabular}{|c|l|c|c|c|c|c|}
\hline \multirow{2}{*}{ No Kriteria } & \multicolumn{5}{|c|}{ Jumlah (\%) } \\
\cline { 3 - 8 } & & STB & TB & CB & B & SB \\
\hline 1 & Keamanan & 0 & 0 & 31 & 69 & 0 \\
\hline 2 & Kenyamanan & 1 & 6 & 62 & 32 & 0 \\
\hline 3 & Kebersihan & 2 & 79 & 15 & 4 & 0 \\
\hline 4 & Ketertiban & 2 & 30 & 59 & 9 & 0 \\
\hline 5 & Kondisi Geometrik & 0 & 8 & 30 & 62 & 0 \\
\hline 6 & Fasilitas Pedestrian & 3 & 79 & 17 & 1 & 0 \\
\hline
\end{tabular}

Keterangan :

STB = Sangat tidak baik

$\mathrm{TB}=$ Tidak baik

$\mathrm{CB}=$ Cekup baik

$\mathrm{B}=$ Baik

$\mathrm{SB}=$ Sangat baik

Berdasarkan survey dengan metode kuesioner mengenai tingkat kebutuhan trotoar terhadap masyarakat dan penilaian masyarakat terhadap jalur pejalan kaki.

Tabel 4.8 Tingkat Kebutuhan Masyarakat Terhadap Trotoar di Jalan Rustam Effendi

\begin{tabular}{|c|c|c|c|c|c|c|}
\hline \multirow{2}{*}{ No. } & \multirow{3}{*}{ Tritik Pengamstan } & \multicolumn{5}{|c|}{ Jumlsh (\%) } \\
\cline { 3 - 7 } & & STP & TP & CP & P & SP \\
\hline 1 & TP 1 & 0 & 2 & 5 & 68 & 25 \\
\hline 2 & TP 2 & 0 & 0 & 0 & 98 & 2 \\
\hline 3 & TP 3 & 0 & 0 & 1 & 38 & 61 \\
\hline 4 & TP 4 & 0 & 0 & 0 & 31 & 69 \\
\hline
\end{tabular}

Sumber : Pengolahan Data

Keterangan :

STP = Sangat tidak perlu

$\mathrm{SP}=$ Sangat Perlu

$\mathrm{CP}=$ Cekup perlu

$\mathrm{P} \quad=$ Perlu

$\mathrm{SP} \quad=$ Sangat perlu

\section{KESIMPULAN DAN SARAN}

\subsection{Kesimpulan}

Setelah melakukan survey kemudian analisa serta pembahasan, maka didapatkan kesimpulan sebagai berikut :

1. Kecepatan rata-rata tertinggi dari ke empat titik pengamatan adalah kecepatan rata-rata pada titik pengamatan 4 yaitu $53,575 \mathrm{~m} / \mathrm{mnt}$. Arus pejalan kaki tertinggi dari keempat titik pengamatan adalah pada titik pengamatan 3 yaitu $17,433 \mathrm{ped} / \mathrm{m} / \mathrm{mnt}$. Kepadatan tertinggi dari ke empat titik pengamatan adalah kepadatan pada titik pengamatan 3 yaitu $0,385 \mathrm{ped} / \mathrm{m} 2$. Ruang pejalan kaki terlebar adalah pada titik pengamatan 4 yaitu 7,673 m2/ped.

2. Berdasarkan perbandingan antara volume per kapasitas menurut Highway Capacity Manual mengenai Level of Services trotoar terhadap karakterisitik pejalan kaki, maka tingkat pelayanan pada titik pengamatan 1 dan titik pengamatan 2 termasuk tingkat pelayanan LOS $\mathrm{C}$ yang menunjukkan ruangnya cukup untuk kecepatan berjalan normal dan untuk mendahului pedestrian lain. Sedangkan untuk titik pengamatan 3 dan titik pengamatan 4 termasuk dalam tingkat pelayanan LOS E yang menunjukkan kecepatan pejalan kaki tidak normal. Berdasarkan perhitungan ruang dan arus pejalan kaki menurut Direktorat Jendral Bina Marga, mengenai Level of Services trotoar terhadap infrastruktur, maka tingkat pelayanan pada titik pengamatan 1 , titik pengamatan 2 , dan titik pengamatan 4 yaitu termasuk tingkat pelayanan A, sedangkan titik pengamatan 3 termasuk tingkat pelayanan B.

3. Berdasarkan data kuisioner dapat disimpulkan bahwa pada titik pengamatan 1 dan 2 sebanyak 166 orang responden atau sebesar $83 \%$ responden menyatakan perlu akan adanya jalur pedestrian, dan pada titik pengamatan 3 dan 4 sebanyak 130 orang responden atau sebesar $65 \%$ responden menyatakan sangat perlu akan adanya jalur pedestrian karena dengan adanya jalur pedestrian yang baik para pejalan kaki akan merasa aman dan nyaman dalam melakukan aktifitas berjalan kaki.

\subsection{Saran}

Saran yang dapat diberikan antara lain :

1. Trotoar harus dikembalikan ke fungsi idealnya, yakni sebagai jalur pedestrian, yang khusus digunakan hanya untuk semua pejalan kaki.

2. Perlu penataan kawasan jalan T.P. Rustam Effendi dengan menyediakan lahan yang tepat untuk pedagang kaki lima berjualan agar terciptanya infrastruktur pejalan kaki yang 
aman, nyaman dan layak untuk para pengguna trotoar.

3. Masyarakat sangat membutuhkan fasilitas pejalan kaki, oleh karena itu sudah semestinya pemerintah membangun fasilitas pejalan kaki beserta fasilitas pendukungnya sehingga fasilitas tersebut dapat digunakan oleh masyarakat. Selain itu pemerintah juga harus memperhatikan fasilitas pejalan kaki yang ada beserta permasalahan yang terjadi pada kondisi eksisting juga melakukan perbaikan dan pemeliharaan berkala terhadap fasilitas pejalan kaki.

\section{DAFTAR PUSTAKA}

Anonim. 2013. Laporan Akuntanbilitas Kinerja Instansi Pemerintah Kota Palembang Tahun 2012.

Departemen Pekerjaan Umum. 1999. Direktorat Jendral Bina Marga, Pedoman

Perencanaan Jalur Pejalan Kaki pada Jalan Umum.

Departemen Pekerjaan Umum. 1990. Direktorat Jenderal Bina Marga, Petunjuk Perencanaan Trotoar No. 007/T/BNKT/1990.

Departemen Pekerjaan Umum. 1995. Direktorat Jenderal Bina Marga, Tata Cara

Perencanaan fasilitas Pejalan Kaki.

Departemen Pekerjaan Umum. 1995. Direktorat Jenderal Bina Marga, Tata Cara Perencanaan Fasilitas Pejalan Kaki di Kawasan Perkotaan No. 011/T/Bt/1995

Khisty, C. John., Lall., B. Kent. 2003. Transportation Engineering. Third Edition, Pearson Education Inc., Upper Saddle River. New Jersey, USA, pp. 557-576

Mutiara Hartawaty, Rooswinany. 2012. Analisis Kebutuhan Infrastruktur Pejalan Kaki (Trotoar) dan Penentuan Nilai Level of Service (Studi Kasus : Jalan Dr. Setia Budi Pasar Baru Baturaja Kabupaten Ogan Komering Ulu).
Putra, Purbanto,dkk. 2013. Analisis Tingkat Pelayanan Fasilitas Pejalan Kaki (Studi Kasus: Jalan Diponogoro di Depan Mall Ramayana).

Roess, Roger P., Prassas, Elena S., McShane, and William R. 2004. Traffic Engineering. Third Edition, Pearson Education Inc., Upper Saddle River. New Jersey, USA, pp. 23-24

Soedradjat, Imam. Pedoman Penyediaan dan Pemanfaatan Prasarana dan Sarana

Ruang Pejalan Kaki di Perkotaan. Penataan Ruang Nasional.

Tamma, Diaz. 2013. Analisis Tingkat Pelayanan Pejalan Kaki/Pedestrian Melintasi Jalan (Studi Kasus di Jalan Tengkuruk Permai)

Tejasomara, Rendy. 2011. Studi Evaluasi Pelayanan Pedestrian pada Jalan Urip Sumoharjo - Panglima Sudirman Surabaya.

Transportation Research Board 2000, Highway Capacity Manual.

Winaya, Putu. 2010. Analisis Fasilitas Pejalan Kaki pada Ruas Jalan Gajah Mada, Denpasar, Bali.

http://www.palembang.go.id 